\title{
Turismo e Lugares: uma visão geográfica
}

\author{
Maria Noémi Marujo ${ }^{i}$ \\ Universidade de Évora (Portugal)
}

Fernanda Cravidão i

Universidade de Coimbra (Portugal)

\begin{abstract}
Resumo: Se por um lado, as últimas décadas do século XX consolidaram e globalizaram o fenómeno turístico, por outro criaram novos turistas e novos percursos, onde a ligação ao território se modifica. O presente artigo analisa, através de uma perspectiva geográfica, a importância do lugar para a actividade turística. As autoras utilizaram como suporte metodológico uma revisão bibliográfica, recorrendo a alguns exemplos práticos. Pretende-se mostrar como as novas práticas turísticas cativam novos públicos, reinventam os territórios, onde o lugar assume novos significados: pela singularidade; pela identidade; pela ligação afectiva e pelo modo como ele é vivido.
\end{abstract}

Palavras-chave: Turismo; Lugar; Imagem; Promoção e Cultura.

Title: Tourism and Places: a geographical perspective

Abstract: If the last decades of the 20th century consolidated and globalised the tourism phenomenon, on the other have created new tourists and new routes, where the connection to the territory changes. This paper examines, through a geographic perspective, the importance of place for tourism. The authors used as a methodological support a literature review, using some practical examples. It is intended to show how the new tourist practices captivate new publics, reinvent the territories, where the place takes on new meanings: by singularity; by identity; by affective link and how it is lived.

Keywords: Tourism; Place; Image; Promotion and Culture.

\footnotetext{
i Licenciada em Comunicação Social e Mestre em Sociologia. Diplomada em Estudos Avançados em Turismo, Lazer e Cultura. Doutoranda em Turismo na Universidade de Évora. Investigadora do CEG-TERRITUR (Centro de Estudos Geográficos - Turismo, Cultura e Território). Docente do Curso de Turismo da Universidade de Évora. E-mail: noemi@uevora.pt

ii Doutorada em Geografia Humana. Professora Catedrática do Departamento de Geografia da Faculdade de Letras da Universidade de Coimbra. Coordenadora do CEGOT (Centro de Estudos em Geografia e Ordenamento do Território). Coordenadora da Linha de Investigação "Paisagens Culturais, Turismo e Desenvolvimento". Coordenadora do 3. ${ }^{\circ}$ Ciclo em Turismo, Lazer e Cultura da Universidade de Coimbra.
} 


\section{Introdução}

O mundo, nos dias de hoje, é mediado pelo fenómeno da globalização e, por isso, é caracterizado por vários autores como um período de constantes e rápidas mudanças, que provoca alterações nos padrões de consumo (Giddens, 1991). Nesse processo da globalização entra o desejo cada vez mais do homem pela fruição de diferentes lugares turísticos que ostentam uma variedade de significados. Os media ao divulgarem espaços e lugares 'paradisíacos' para serem contemplados ou interpretados exercem um papel crucial nesse acto de consumo. De facto, a forma como a imagem de um lugar é veiculada pelos meios de comunicação pode ser fundamental para o processo de decisão do turista na visita a um país ou região. Por isso, no campo da promoção turística, os lugares são apresentados cada vez mais aos potenciais visitantes como um destino que apela a diferentes olhares. Veja-se o exemplo da cidade de Coimbra que nas suas campanhas publicitárias 'vende' o lugar para ser consumido em diferentes perspectivas: ' $\mathrm{C} i$ dade Universitária', 'Cidade Histórica', 'Cidade do Conhecimento' ou 'Cidade do Fado'. Ou então o caso da cidade de Évora que promove o lugar para ser experienciado através da cultura e do património: 'Cidade da Cultura', 'Cidade do Património Mundial' ou 'Cidade Museu'. Tais slogans suscitam no ser humano o desejo de experienciar, de sentir e conhecer as distintas culturas do lugar, ou seja, despertam nele o consumo pelas singularidades alheias. Por outro lado, e em termos turísticos, os slogans atribuídos a uma cidade ou vila servem também para afirmar o lugar.

É um facto, que a criação e difusão rápida de novas tecnologias propiciaram um encurtamento do tempo e das distâncias entre lugares, possibilitando e tornando mais rápido o movimento de pessoas. Por isso, a globalização de certa forma procura apresentar o mundo como um todo. "Tudo se desterritorializa e reterritorializa. Não somente muda de lugar, desenraíza-se circulando pelo espaço, atravessando montanhas e desertos, mares e oceanos, línguas e religiões, culturas e civilizações. As fronteiras são abolidas ou tornam-se irrelevantes ou inócuas..." (Ianni, 1996: 169). Com a globalização, o local e o global aproximaram-se ou melhor "a ordem global invade o local, impondo-lhe a sua única e própria racionalidade através das suas inovações, que passam a ser imitadas" (Santos, 1994: 272). A articulação mediatizada entre o local e o global gera uma representação sobre povos e lugares e incita a vivenciá-los (Avighi, 2000). É óbvio que as informações sobre turismo divulgadas pelas redes globalizadas criam uma representação global de lugares e de culturas e incentivam o desejo de visitá-los, de observar, interpretar e consumir a cultura. Deste modo, os mais longínquos lugares têm sido visitados, desenvolvendo-se gradualmente uma cultura do turismo, que o coloca como uma das mais importantes faces da globalização, e que contribui para diminuir as distâncias entre as diversas partes do globo (Dias, 2003). Assim, com a globalização e a presença dos media, "...todos os lugares parecem estar em todos os lu- gares. É justamente a ausência de todos os lugares num certo lugar que desperta, fascina e atrai" (Castrogiovanni, 2003: 45). Todavia, se é verdade que há alguns anos atrás, se argumentava que a globalização iria fazer desaparecer as diferenças locais ou regionais, homogeneizando o espaço e a sociedade. Também, não é menos verdade que hoje, o debate já não se coloca mais nestes termos, pois tanto as particularidades locais, como os localismos ou os regionalismos emergiram deste global (Luchiari, 2001). Para esta autora, a globalização passou a valorizar as diferenciações dos lugares. Tais diferenças encontram-se muitas vezes nas iniciativas locais que estão "enraizadas no espírito do lugar, na especificidade dos contextos..." (Santos, 2002: 75).

No estudo do turismo, o que atrai muitos geógrafos é principalmente a visão que ele proporciona sobre a natureza da estrutura do lugar, a criação e a experiência do lugar (Lew, 2003). "Os lugares fornecem temas fundamentais para o estudo do turismo porque eles são as entidades e os cenários através dos quais os seres humanos definem as suas vidas e as sociedades se envolvem na vida quotidiana" (Snepenger et al, 2004: 108). Se um lugar é socialmente e culturalmente construído, então são necessárias pesquisas para uma maior compreensão da política do lugar no lazer e no turismo (Stokowski, 2002).

\section{O turismo e os lugares}

O conceito de lugar é abordado de acordo com as perspectivas das diferentes áreas do conhecimento e, por isso, tem sido alvo de várias interpretações ao longo do tempo. O lugar possui uma estrutura complexa e diferenciada composta por um conjunto de componentes interligados e interdependentes, tais como: sujeito e objecto, espaço e tempo, 'eu' e o 'outro' (Malpas, 2004). Para Santos (2008: 339), "cada lugar é, ao mesmo tempo, objecto de uma razão global e de uma razão local, convivendo dialecticamente". O lugar faz parte da essência do ser humano (Cravidão, 2006), engloba elementos físicos e culturais e, no caso do turismo, ambos os elementos são necessários para que o turista possa de certa forma compreender e apreciar o lugar que está a visitar. "O lugar é um elemento fundamental na formação e construção das culturas turísticas" (Wearing et al, 2010: 80).

No campo da geografia o lugar adopta diferentes dimensões e componentes. Frey (2009) argumenta que o recurso do lugar está estruturado em três dimensões: a) a constituição físico-material do lugar e consequentes formas possíveis de utilização; b) o simbolismo cultural que o lugar utiliza e que contribui para criar a identidade; c) o ambiente da vizinhança do lugar que, pela sua utilização e activação, estrutura o habitat sócio-espacial do lugar. Segundo Agnew (1987), o lugar pode ser constituído por três elementos: a)local: fronteira onde são estabelecidas relações sociais; b) localização: área geográfica que abrange o limite para a interacção social definido por processos sociais e económicos mais vastos; c) sentido de lugar: 
construção do sentimento local. No turismo, este último elemento está fortemente relacionado com os aspectos subjectivos de um determinado sítio como, por exemplo, a memória, a ligação espiritual ou a nostalgia que faz com que muitos turistas regressem a esse mesmo lugar. Portanto, o sentido de lugar está intimamente associado à capacidade de reconhecer e responder às diversas identidades de um lugar. "O senso de lugar surge quando as pessoas sentem uma ligação especial ou relação pessoal com uma área na qual o conhecimento local e os contactos humanos são significativamente mantidos" (Sharma, 2004: 278). Por outro lado, e ainda dentro do contexto do sentido de lugar, os lugares podem funcionar como objectos de representação (filmes, telenovelas, documentários) para influenciar ou motivar a visita de potenciais turistas. Aliás, aquilo que cada vez mais se consome nas práticas turísticas é os signos ou as representações de um lugar.

A epistemologia fundamental da geografia humana é que o homem estrutura a sua experiência do mundo através da criação de lugares (Lew, 2003). O autor afirma que os lugares podem ser criados através da percepção ou, então, o homem pode dar forma ao lugar para reflectir a sua identidade. Na geografia humana, o lugar é entendido como uma expressão de vivência, como um produto da experiência humana (Ringer, 2003). "O lugar é produto das relações humanas, entre o homem e natureza, tecido por relações sociais que se realizam no plano vivido, o que garante a construção de uma rede de significados e sentidos que são tecidos pela história e cultura civilizadora produzindo a identidade" (Carlos, 1999: 29). O lugar também pode ser percebido como um espaço que possui valor e significados dentro de uma cultura, ou seja, é um centro de significados construído pela experiência (Tuan, 1977). O autor realça que "o lugar é conhecido não só através dos olhos e da mente mas também através dos modos mais passivos e directos da experiência, que resistem à objectivação. Conhecer um lugar totalmente significa conhecê-lo de uma forma abstracta e conhecê-lo também como uma pessoa conhece outra" (Tuan, 1975: 152). Se para este autor os lugares são uma construção da experiência em todas as suas modalidades e se possuem valor cultural, então eles apresentam significados diferentes para os diversos níveis de procura turística.

Um lugar turístico pode ser entendido como um aglomerado de lugares que produz experiências para as diferentes tipologias dos turistas. Assim sendo, "os lugares são o ponto de encontro para as experiências em turismo, o contexto para a interacção social e psicológica, e o fenómeno pelo qual este comportamento pode ser descrito, explicado e previsto" (Snepenger et al, 2007: 310). O turismo promove encontros com os lugares e, por isso, eles são um elemento decisivo da actividade turística. Nestes encontros com o lugar, "as relações sociais estão situadas e consubstanciadas em lugares específicos onde acontece o turismo...Tais lugares são imersos em valores e sentimentos" (Crouch, 2000: 71). Pearce (2001) refere que a literatura é praticamente silenciosa sobre o que constitui um lugar turístico, como o lugar é definido e como é ge- rido. Por definição, "os lugares turísticos são lugares em que há turistas, onde fomos precedidos e onde seremos seguidos por muitos outros" (Knafou, 2001: 64). Logo, sem turistas não há práticas turísticas, não existe lugar turístico. Como afirma Cravidão (2006), os lugares constituem cada vez mais o centro de novas práticas turísticas. $\mathrm{E}$, portanto, é a intencionalidade e a prática do turista que identificam o lugar (Almeida, 2006). Para esta autora "um lugar turístico adquire significado para o turista porque ele é outro, porque ele rompe com as qualidades do seu lugar de vida e, sobretudo, porque ele será aquele espaço que lhe acena com possibilidades de corresponder às suas expectativas. $\mathrm{O}$ que o turista busca é uma alteridade. A escolha dos lugares e o modo de deslocamento ocorrem em função disso" (Almeida, 2006: 111). A autora ressalta que nos lugares turísticos, os turistas contemplam as representações, as ideias da paisagem e dos objectos que são promovidos pelos meios de comunicação. E por isso, "as viagens àquele lugar, ou melhor, àquelas representações, destinam-se à procura daquela imagem mentalizada e à confirmação da sua existência pelo facto de ter estado lá" (Almeida, 2006: 113). De acordo com Sobrinho (2004), o conceito de lugar turístico refere-se aos lugares que já foram apropriados pela prática social do turismo, mas também aos lugares considerados potencialmente turísticos. Assim, e para este autor, o lugar turístico está imbuído de uma visão materialista de fruição dos lugares para os interesses do capital. O autor sublinha ainda que "o entendimento da produção dos lugares para o turismo dáse por meio da linguagem que o representa e constitui a mediação necessária para a sua percepção: não podemos entender o lugar turístico senão por meio dos seus signos" (Sobrinho, 2004: 74). Fratucci (2000) argumenta que o turismo possibilita a construção de um lugar onde a marca principal está na troca de experiências pessoais entre os residentes e o turista. Assim, o lugar turístico pode ser entendido como o lugar onde turistas e anfitriões podem estabelecer intercâmbios culturais. "O lugar turístico...é o território onde o turismo se realiza, e onde há a ocorrência de interacções e inter-relações temporárias entre o anfitrião e o turista, aos quais irão permitir um contacto directo, sem barreiras (físicas ou simbólicas) entre eles e o reconhecimento da existência do outro, recíproca e simultaneamente" (Fratucci, 2000: 131). Sublinhe-se que para o turista essa experiência, caso seja positiva, pode contribuir para o seu enriquecimento pessoal ou satisfação das suas expectativas e motivações que o levaram a realizar essa viagem. "Para o turista o lugar turístico é o espaço e o momento efémero de uma experiência real e directa, de descoberta de si e do outro" (Fratucci, 2000: 131). No entanto, para o anfitrião a experiência irá sobretudo proporcionar a consolidação da sua identidade com o seu lugar. Assim, a interacção social que as comunidades anfitriãs estabelecem com os turistas pode ser vista como um factor de fortalecimento da sua consciência de pertença ao lugar. Como argumenta (Meethan, 2001: 139), "pertencer a um lugar é conhecer os significados das suas formas simbólicas". 
Baerenholdt et al (2004) identificaram no campo do turismo cinco dimensões dos lugares turísticos: ambiente físico, personificação, sociabilidade, memória e imagem. Estas dimensões contribuem fortemente para o processo de satisfação ou insatisfação da experiência do turista sobre o lugar que está a visitar. Williams (2009) refere que a distinção cultural dos lugares turísticos é evidente em diversas formas, mas que há duas notas que devem ser levadas em conta. A primeira está relacionada com os papéis que os seres humanos atribuem aos lugares turísticos. Ou seja, o autor realça que os lugares turísticos precisam de servir um propósito: como locais de diversão, de emoção e desafio, de espectáculo ou então como lugares de memória. Todavia, este geógrafo afirma que nenhum destes atributos existe isoladamente, pois "são construções culturais que reflectem os valores, crenças, costumes e comportamentos, através das quais nós nos definimos como indivíduos e como membros de uma sociedade" (Williams, 2009: 183). Em segundo lugar, o autor refere que os lugares turísticos são geralmente distinguidos pela incidência da prática turística reconhecível. Ou seja, é a prática turística que torna distintos os diferentes lugares turísticos. Assim sendo, os lugares turísticos são "produzidos activamente através das performances dos turistas que se reúnem em locais favorecidos e cuja presença e acções, por sua vez, reforça a natureza e o carácter desses locais como lugares turísticos" (Williams, 2009: 183). Ainda segundo este autor, o turismo cruza-se com o lugar nos seguintes aspectos: a) Muitas formas do turismo estão fortemente enraizadas no sentido de lugar; b) As percepções e motivações dos turistas são directamente moldadas pelas formas pelos quais eles imaginam os lugares e são estimulados a imaginar os lugares pela actividade turística; c) Os lugares turísticos, muitas vezes, possuem fortes qualidades simbólicas e representações que formam a base primária da sua atracção; d) O turismo é um dos principais meios através do qual é possível construir e manter a identidade de um lugar; e) O turismo pode ser um meio pelo qual os seres humanos desenvolvem vínculos pessoais com o lugar e para os quais o lugar se torna um local com significado; f) Os lugares turísticos são locais de memórias para muitos turistas. As fotografias e outras recolhas de lembrança sobre os lugares visitados são uma forma de recordar as experiências turísticas; g) Os lugares turísticos promovem o sentimento de pertença a um local (Williams, 2009).

O turismo (re) inventa lugares para consumo turístico. Segundo Knafou (1991), a invenção do lugar turístico pressupõe um desvio do uso predominante dos locais (o poder subversivo do turismo) e a incorporação de novos territórios para lugares turísticos (poder de conquista do turismo). O turismo cria o lugar turístico (Ferrara, 2002), mas é também considerado como um agente activo na destruição criativa de lugares em que pode ser um processo transformador produtivo, violento, contestado ou bemvindo (Crang, 2004). O turismo é, portanto, “...um produto da mobilidade. Tem por especificidade percorrer o espaço, mas a sua lógica conduz também à fixação. Num qualquer lugar privilegiado, que modela, adapta, transforma, fre- quentemente devora, não raras vezes descaracteriza, e para alguns autores, concorre mesmo para a construção de não - lugares" (Cravidão, 2004: 311). De facto, o turismo muitas vezes "transforma tudo o que toca em artificial, cria um mundo fictício e mistificado de lazer, ilusório onde o espaço se modifica em cenário, 'espectáculo' para uma multidão amorfa mediante a criação de uma série de actividades que conduzem a passividade, produzindo apenas a ilusão da evasão e, desse modo, o real é metamorfoseado, transfigurado para seduzir e fascinar. (...) Ao vender-se o espaço produz-se a não-identidade e, com isso, o não lugar, pois longe de se criar uma identidade produzse mercadorias para serem consumidas..." (Carlos, 1999: 26).

\section{A promoção e imagem dos lugares turisticos}

Vivemos actualmente uma época na qual a publicidade e os media invadem cada interstício da sociedade. Tal facto, estimula no ser humano uma propensão para o consumo que antecede à produção material e imaterial e que procura despertar a necessidade do lazer e do turismo. $\mathrm{O}$ sucesso das regiões, em termos turísticos, passa pela existência de alguns factores primordiais, como por exemplo, os atractivos, as infra-estruturas turísticas, a própria localização, etc. Porém, existe um factor determinante para que o consumidor visite uma determinada região e não outra e que, muitas vezes, é ignorado: A imagem do lugar turístico. Ela, de certo modo, forma a base das expectativas dos turistas. Num mundo em que quase tudo é representado através das imagens, torna-se quase impossível o ser humano viver sem a produção delas (Marujo, 2008). A imagem de um destino, veiculada pelos meios de comunicação, distingue os lugares turísticos uns dos outros e é

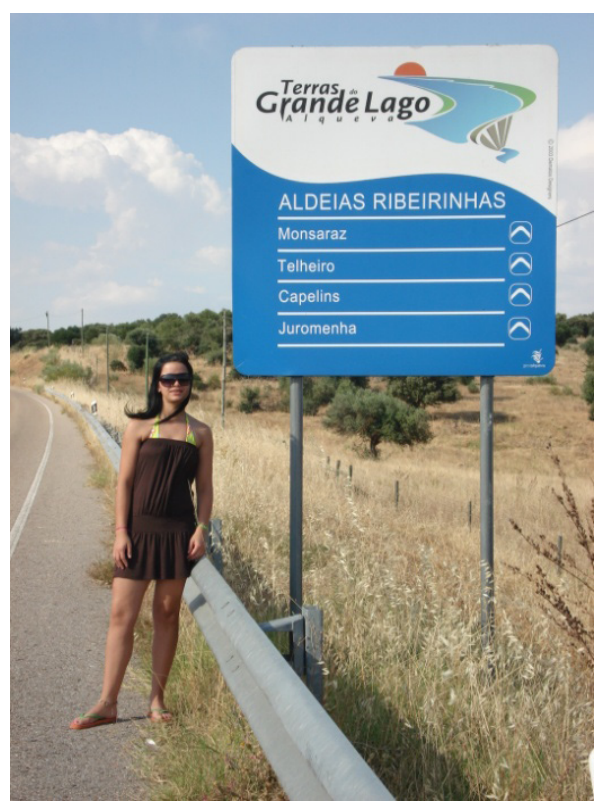

Figura I - Confirmação do turista no lugar Foto: Maria Marujo (2010) 
também um elemento fundamental do processo de decisão dos turistas. Para Giotart "a força da imagem que caracteriza os lugares turísticos corresponde a uma espécie de território mental onde a realidade e mitos vão servir de suporte à descoberta ou (redescoberta) e à viagem" (Cravidão, 2004: 311).

Urry (1996: 18), refere que "os lugares são escolhidos para serem contemplados porque existe uma expectativa, sobretudo através da fantasia, em relação a prazeres intensos, seja em escala diferente, seja envolvendo sentidos diferentes daqueles com que habitualmente nos deparamos". Tal expectativa, segundo o autor, é construída e mantida por uma multiplicidade de práticas não-turísticas como, por exemplo, o cinema, a televisão, a literatura e as revistas que constroem e reforçam o olhar. De facto, os meios de comunicação promovem a imagem de determinados lugares definindo-os como distintos e elegantes e, portanto, visitar esse lugar passa a ser moda para muitos turistas. Na verdade, muitos dos potenciais turistas nem sabem onde ficam esses lugares promovidos pelos media (Marujo, 2008). Todavia, "o importante não é o conhecimento geográfico, mas a possibilidade de visitar um lugar em evidência e chique” (Barbosa, 2001: 35). Refira-se o caso da Barragem de Alqueva (o maior lago artificial da Europa) que se tornou num destino turístico para ser consumido por diferentes olhares. Chegados ao destino, os turistas procuram contemplar o lugar atribuindo-lhe diversos significados. O tempo dos turistas perde-se, também, pela procura do melhor espaço para captarem imagens (fílmicas ou fotográficas) que envolvam os elementos do novo lugar e que, mais tarde, ajudam a recordar esse destino visitado. Através da fotografia e do olhar, o turista procura criar uma narrativa própria sobre o lugar que está a visitar. Fotografar ou filmar um lugar constitui, para um turista, a estruturação do seu testemunho sobre a realidade que está a captar. Significa, também, um meio de recordar a sua experiência. Essa prática turística termina quase sempre com uma foto do turista a confirmar a sua presença no lugar (Figura I).

O desejo de experienciar e de conhecer suscitado pelas imagens que o turismo cria e pela publicidade que lhe dá corpo, faz com que o homem procure cada vez mais a fantasia, o simulacro, o exotismo, a nostalgia, o novo, o diferente (Almeida, 2009). Mas o turista, antes de chegar ao destino, já produziu representações mentais sobre o lugar que pretende visitar. Tais representações, ocorrem a partir do momento da intenção da viagem e constituem um universo elaborado pelo imaginário, que vai ser desvendado na realização dessa viagem, quando por sua vez se elaboram novas representações (Marujo, 2008). Assim sendo, o turista constrói uma imagem mental que, segundo Barbosa (2001), envolve a criação de uma fantasia ou de um sonho, e o turista passa a imaginar o lugar como se lá estivesse. O seu imaginário turístico é, portanto, constituído por um conjunto de crenças e imagens que ele faz do lugar turístico, bem como pelas motivações e pelo conjunto de experiências que pode adquirir no lugar visitado.

É óbvio, que a promoção do turismo nos meios de comu- nicação, especialmente na Internet, aguça o apetite pela procura de novos lugares que, de facto, assumem valores e significados especiais para aqueles que os experienciam ou consomem. Todavia, e uma vez no destino, o turista reconhece as imagens antes veiculadas pelos meios de comunicação, mas não estabelece uma relação com o lugar, não descobre o seu significado. Logo, e como sublinha Carlos (1999), o turismo cria uma ideia de reconhecimento do lugar mas não o seu conhecimento, pois os passos dos turistas e visitantes são guiados por rotas, ruas pré-estabelecidas, por roteiros gastronómicos, históricos, etc. Para a autora, os lugares fragmentam-se, o feio é excluído, o turista é afastado do pobre, do usual. O tempo do turista acelera-se na busca de um pseudo-conhecimento de lugares, pois ele não tem tempo para contemplar o lugar (Carlos, 1999)

Na promoção, o lugar turístico apresenta-se como uma representação social que resulta não só do contexto social que pretende retratar, mas também daquele ao qual se dirige. A promoção de lugares, para além de exercer um papel fundamental na construção social de mitos locais, contribui para a produção cultural e o consumo de paisagens, espaços e lugares de pessoas distintas em tempos diferentes (Morgan, 2004). Por isso, a atractividade dos lugares precisa de ser constantemente vendida, o que faz com que os lugares sejam continuamente recriados, ou seja, padronizados em estilo, estética e atendimento (Luchiari, 2001). Hoje, os lugares tornaram-se objecto de estratégias temáticas, de designação, revisão, de re-imaginação e da aplicação generalizada de técnicas de marketing (Hughes, 2003). A promoção dos lugares envolve a combinação de numerosas variáveis para satisfazer as necessidades do mercado-alvo das empresas e alcançar os objectivos das organizações promotoras. Todavia, o marketing criado à volta dos lugares ou das paisagens acaba, muitas vezes, por privilegiar determinados lugares em detrimento de outros, considerados menos atractivos, causando graves problemas sociais (Cruz, 2002).

Note-se que um lugar turístico não pode ser transportado até ao consumidor e, portanto, este tem que ser atraído para esse local. É através da linguagem publicitária que os lugares se transformam em "verdadeiros objectos de consumo, socialmente significantes e passíveis de apropriação material ou simbólica, por parte do turista" (Conceição, 1998: 83). Assim, a promoção de um lugar ocorre através de diversas esferas comunicacionais: publicidade, relações públicas, media, etc. Promover um lugar turístico significa comunicar aos potenciais turistas que o lugar (x) ou (y) é capaz de satisfazer os seus desejos e necessidades. É a antecipação da experiência proporcionada no lugar turístico que se assume como a principal característica de toda a estratégia promocional das entidades públicas e privadas. É através da antevisão que “...a viagem ganha um contorno mais concreto aos olhos do potencial turista" e que o lugar "renasce como um verdadeiro sonho" (Conceição, 1998: 73). A promoção dos lugares, veiculada pelos promotores do turismo, mostra o mundo "como uma imagem, convidando o espectador a tornar-se num 
viajante imaginário para um lugar imaginado" (Morgan, 2004: 205). O autor sublinha ainda que é na promoção dos lugares que se encontra a mediação da relação entre o visitante e o lugar.

\section{Conclusão}

O turismo é um fenómeno multidimensional que envolve o movimento temporário de pessoas para diversos destinos turísticos. Para a geografia, um destino turístico pode ser percebido como uma atracção, como uma unidade geográfica ou como um lugar onde as práticas turísticas acontecem. Hoje, o turismo apropria-se cada vez mais dos territórios e turistifica-os criando novos lugares turísticos para serem consumidos. Os elementos culturais materiais e imateriais de um país ou região são constantemente mencionados como criadores de lugares turísticos dando, deste modo, origem a novas identidades. Assim, e para atrair mais turistas ou visitantes, os promotores do turismo 'vendem' esses novos destinos atribuindo-lhes slogans persuasivos - "Cidade da Arte"; "Cidade do Património"; "Cidade da Cultura" ou "Capital do Vinho"; "Capital da Gastronomia"; "Capital do Artesanato" - que dão forma a novas práticas turísticas. Nos lugares turísticos, o turista procura contemplar as representações que foram veiculadas pelos media. De facto, os meios de comunicação fabricam imagens sobre os mais distintos lugares incentivado, cada vez mais, o desejo pela viagem. Assim, na maior parte dos casos, as viagens a essas localidades turísticas têm como objectivo final o consumo da imagem idealizada e a confirmação da sua presença no lugar. "O lugar inventado para e pelo turismo transforma-se no outro, aquele desejado e esperado pelos turistas. Estes visitam, participam, aceitam o proposto pelo receptivo e, quando retornam aos seus lugares, é com sentimento de terem conhecido um novo lugar, uma nova cultura" (Almeida, 2006: 119-120).

A criação desses novos lugares que englobam o destino turístico revoluciona, por vezes, os territórios e as relações sociais provocando diversos impactos nas comunidades locais. De facto o turismo acaba, muitas vezes, por criar lugares turísticos que não têm nenhum reconhecimento com o local formando, deste modo, os não-lugares. É o caso de certas cidades, que para atraírem mais turistas, entram num "mundo de faz-de-conta" (Barbosa, 2001: 11). Os turistas estimulados pelas imagens do novo destino acabam sempre por visitar esse não-lugar. "Os turistas sabem que o lugar visitado é um simulacro e é, talvez, essa capacidade de poder ver o falso que se transforma na maior atracção. O olhar do turista está direccionado para as aparências, é o faz-de-conta" (Barbosa, 2001: 56). Refira-se que um lugar turístico deve valorizar a singularidade de um determinado local. É, portanto, a identidade que um lugar abarca que o diferencia dos outros lugares. Assim, o lugar artificial inventado pelo turismo, ou melhor pelo destino turístico, perde o seu significado porque ele não tem identidade.
No turismo, não interessa somente o carácter autêntico das suas gentes, mas também os aspectos mais singulares de cada lugar. Se é verdade que os lugares se mundializam, também é um facto que cada vez mais eles se tornam únicos. É o lugar que promove novas formas de consumir os diferentes territórios. É no lugar que se constroem as relações sociais, que "...se (re) cria a identidade, a singularidade cultural" (Cravidão, 2004: 312). De facto, num mundo globalizado, a personalidade de um lugar encerra diferentes identidades que são, cada vez mais, trabalhadas para consumo dos turistas. E, portanto, "a globalização, ao mesmo tempo em que ameaça nivelar os lugares, fá-los reafirmarem-se como nunca antes, mas à luz de novas relações de força. Nesta óptica, o multicultarlismo...deixa supor que aquilo que era um lugar uniforme, uma cidade, por exemplo, passe a assumir várias identidades espaciais" (Yázigi, 2001: 284).

Concluímos que o turismo pode ser entendido como o consumo dos lugares, onde apela aos cinco sentidos. Praticar turismo implica consumir sítios, 'olhar' e interpretar o significado das diferentes paisagens que constituem esses lugares.

\section{Bibliografia}

\section{Agnew, J.}

1987 Place and politics: the geographical mediation of state and society. Boston: Allen \& Unwin.

Almeida, M.

2006 "Cultura, turismo e identidade: a produção do ser e do lugar turístico". In SILVA, J. et al (Orgs), Panorama da geografia brasileira, São Paulo: ANNABLUME.

Almeida, M.

2009 "A geografia imaginária dos lugares turísticos". In XIII Simpósio Brasileiro de Geografia Física Aplicada, Universidade Federal de Viçosa http://www.geo.ufv. br/simposio/ (acesso, 29-06-10).

Avighi, C.

2000 "Turismo, Globalização e Cultura". In Lage, B. e Milone, P., Turismo: Teoria e Prática, São Paulo: Atlas.

Baerenholdt, J. et al

2004 Performing tourist places: new directions in tourism analysis. England: Asghate.

Barbosa, Y.

2001 O despertar do turismo: um olhar crítico sobre os não-lugares. São Paulo: Aleph.

Carlos, A.

1999 "O turismo e a produção do não-lugar". In YÁZIGI et al, Turismo: espaço, paisagem e cultura. São Paulo: HUCITEC.

Castrogiovanni, A.

2003 "Turismo e espaço: Reflexões necessárias na pós-modernidade", In Gastal, S. e Castrogiovanni, A. (orgs). Turismo na pós-modernidade (des) inquietações. Porto Alegre: EDIPUCRS. 
Conceição, C.

1998 Promoção turística e (re) construção social da realidade, Sociologia - Problemas e Práticas, N. ${ }^{\circ} 28$, ISCTE.

Crang, $\mathrm{M}$.

2004 "Geografias culturais do Turismo". In LEW et al, Compêndio de Turismo. Lisboa: Instituto Piaget.

Cravidão, $\mathrm{F}$.

2004 "Turismo e cultura: o lugar dos lugares". Revista Turismo - Visão e Acção, 6(3): 309-316.

Cravidão, F.

2006 "Turismo e cultura: dos itinerários ao lugar os lugares", In Fonseca, Maria Lucinda, Desenvolvimento e território - Espaços Rurais Pós-agrícolas e Novos Lugares de Turismo e lazer. Lisboa pp. 269-279.

Crouch, D.

2000 "Places around us: embodied lay geographies in leisure and tourism", Leisure Studies, 19(2).

Cruz, R.

2002 "As paisagens artificiais criadas pelo turismo". In YÁZIGI, E. (org), Turismo e Paisagem. São Paulo: Contexto. Dias, R.

2003 Sociologia do turismo. São Paulo: Atlas.

Ferrara, L.

2002 "Os lugares improváveis", In YÁZIGI, E. (org.). Turismo e paisagem. São Paulo: Contexto

Fratucci, A.

2000 "Os lugares turísticos: territórios do fenómeno turístico". GEOgraphia, 2(4), Universidade Federal Fluminense.

Frey, $\mathrm{O}$.

2009 "Creative places and cultural matrices of the city", in Maciocco, G. e Serreli, S. (eds.), Enhancing the City: new perspectives for tourism and leisure. London, New York: Sprenger

Giddens, Anthony

1991 Modernity and self-identity, Cambridge: Polity Press.

Hughes, G.

2003 "Tourism and the semiological realization of space". In RINGER, G., Destinations: Cultural landscapes of tourism. London and New York: Routledge.

lanni, Octávio

1996 Teorias da globalização, Rio de Janeiro: Civilização Brasileira.

Knafou, $\mathrm{R}$

1991 "L'invention du lieu touristique: la passation d'un contrat et le surgissement simultané d'un nouveau territoire", Revue de géographie alpine, 4

Knafou, R.

2001 "Turismo e território: para um enfoque científico do turismo". In Rodrigues, A. Turismo e geografia. Reflexões teóricas e enfoques regionais. São Paulo: HUCITEC.

Lew, A.

2003 "Tourism in places and places in tourism". Tourism Geographies, 5(2): 121-122.

Luchiari, M.

2001 "Urbanização turística: um novo nexo entre o lugar e o mundo", In Serrano, C. et al (orgs.), Olhares contempo- râneos sobre o turismo, São Paulo: Papirus.

Malpas, $\mathrm{J}$.

2004 Place and experience: A Philosophical Topography. UK: Cambridge University Press.

Marujo, M.

2008 Turismo e comunicação. Castelo Branco: RVJeditores. Meethan, $\mathrm{K}$.

2001 Tourism in global society: place, culture and consumption. New York: Palgrave.

Morgan, N.

2004 "Problematizar a promoção de lugares", In LEW et al, Compêndio de Turismo. Lisboa: Instituto Piaget.

Pearce, D.

2001 "An Integrative Framework for Urban Tourism Research", Annals of Tourism Research, 28(4): 926-946.

Ringer, G.

2003 Destinations: Cultural landscapes of tourism. London and New York: Routledge.

Santos, Boaventura de Sousa

2002 A globalização e as ciências sociais. São Paulo: cortez.

Santos, M.

1994 O novo mapa do mundo: fim de século e globalização. São Paulo: HUCITEC.

Santos, M.

2008 A natureza do espaço: técnica e tempo, razão e emoção. São Paulo: EDUSP.

Sharma, K.

2004 Tourism and Regional Development. New Delhi: Sarup \&Sons.

Snepenger, D. et al

2004 "Normative Meanings of Experiences for a Spectrum of Tourism Places", Journal of Travel Research, 43(2): 108-117.

Snepenger, D. et al

2007 "Meanings and Consumption Characteristics of Places at a Tourism Destination". Journal of Travel Research, 45(3): 310-321.

Sobrinho, $F$.

2004 "Lugares, olhares e imagens: uma breve discussão sobre palnejamento turístico". Revista Múltipla, 16, Brasília: UPIS

Stokowski, P.

2002 "Language of Place and Discources of Power: Constructing New Senses of Place", Journal of Leisure Research, 34(4): 368-382.

Tuan, Yi-Fu

1975 "Place: an experiential perspective", The Geographical Review, LXV(2).

Tuan, Yi-Fu

1977 Space and place: the perspective of experience. Minneapolis: University of Minnesota Press.

Urry, J.

1996 O olhar do turista: lazer e viagens nas sociedades contemporâneas, São Paulo: Studio Nobel - Sesc.

Wearing, S. et al

2010 Tourist Cultures: Identity, Place and the Traveller. 
London: Sage Publications.

Williams, S.

2009 Tourism Geography: a new synthesis. New York: Routledge.

Yázigi, E.

2001 A alma do lugar: turismo, planejamento e cotidiano. São Paulo: Editorial Contexto.

Recibido:

Reenviado:

Aceptado:

Sometido a evaluación por pares anónimos
$09 / 03 / 2011$

$25 / 08 / 2011$

$09 / 09 / 2011$ 